\title{
A Construção da
}

\section{Visualidade da Revista}

Sesinho: Codificação e

Decodificação em Seis

Décadas de História

\author{
Silvio Ricardo Demétrio \\ Graduado em Comunicação Social \\ Jornalismo pelaUniversidade Estadual \\ de Londrina (1994), mestrado \\ em Ciências da Comunicaçãopela \\ Universidade de São Paulo(2001), \\ doutorado em Epistemologia da \\ Pesquisa EmComunicação pela \\ Universidade de São Paulo (2007). \\ Professor adjunto daUniversidade \\ Estadual de Londrina na graduação \\ em Comunicação Social -Jornalismo \\ /programa de mestrado em \\ Comunicação Visual.
}

\section{Marlene Ferreira Royer}

Graduada em Comunicação Social Habilitação Relações Públicas pela Universidade Estadual de Londrina (UEL). Especialista em Comunicação Empresarial e Mestranda em Comunicação Visual, pela mesma instituição, onde atua como professora colaboradora.

E-mail: marlene@royer.com.br.
Resumo: Este trabalho analisa as capas da revista de história em quadrinhos Sesinho e a construção de sua visualidade em épocas distintas, no período de 1947/1960 e 2001/2011, tendo como aporte teórico-metodológico o modelo de Stuart Hall, que coloca a comunicação como uma estrutura produzida e sustentada na articulação de momentos distintos, porém interligados, que consistem nas fases de produção-circulação, distribuição e consumo. Neste processo, a codificação e a decodificação representam práticas discursivas de produção de sentido, que podem influenciar, entreter, instruir e persuadir o receptor. $O$ objeto deste estudo é a revista Sesinho, criada há 65 anos pelo SESI - Serviço Social da Indústria e, mesmo dirigida ao público infantil, seu conteúdo vem sendo absorvido por diferentes gerações. A análise da revista Sesinho ocorreu com a seleção de materiais de diferentes épocas, entre 1940 e 1960 e a seleção das capas entre as que foram produzidas na primeira década do século XXI.

Palavras-chave: Revista Sesinho; Visualidade; Codificação e Decodificação.

Abstract: This paper analyzes the covers of the comics magazine Sesinho and the visual construction in different times, in the periods 1947\1960 and 2001\2011, using as theoretical method Stuart Hall's model, that defines communication as a structure that is created and sustained in the articulation of different but linked moments, that consists in the steps of production-circulation, distribution and absorption. In this process, the coding and decoding represent discursive practices of production of meaning, that can influence, entertain, instruct and persuade the receiver. This study's object is the magazine Sesinho, created 65 years ago by SESI - Serviço Social da Indústria and, even directed to children, its content is being absorbed by different generations. The magazine's analysis was made with selection of the material from different years, between 1940 and 1960, and the covers produced in the first decade of XXI century.

Keywords: Sesinho magazine; Visuality; Coding and Decoding.

\section{Introdução}

Nos estudos dos processos comunicativos, o modelo de Stuart Hall (2003), apresentado no texto Codificação/Decodificação, coloca a comunicação como uma estrutura produzida e sustentada na articulação de momentos distintos, porém interligados, que consistem nas fases de produção-circulação, distribuição e consumo. 
Isto seria pensar o processo como uma complexa estrutura em dominância, sustentada através da articulaçãode práticas conectadas, em que cada qual, no entanto, mantém sua distinção e tem sua modalidade específica, suas próprias formas e condições de existência (HALL, 2003:387).

O objeto deste circuito, a comunicação, é composto por "significados e mensagens sob a forma de signos-veículo de um tipo específico, organizados, como qualquer forma de comunicação ou linguagem, pela operação de códigos dentro da corrente sintagmática de um discurso" (HALL, 2003: 387). É na forma discursiva que a circulação do produto se efetiva e chega para a recepção de diferentes audiências. Ao atingir o público, o produto comunicativo deve ser traduzido e transformado em práticas sociais; assim, o circuito do processo de comunicação completa-se e produz seus efeitos e, "antes que qualquer mensagem possa ter um "efeito", ou tenha um uso específico, ela deve ser apropriada como um discurso significativo e ser significativamente decodificada" (HALL, 2003: 390).

O estudo de Stuart Hall coloca o receptor em evidência e passa a ser referência para os estudos de recepção a partir da década de 1970, permitindo que as análises deixem de ver o receptor como elemento secundário, e passem a vê-lo como sujeito que determina a continuidade e efetivação dos processos comunicativos, que marca a relação entre a mídia e o público.

Nesta mesma perspectiva, Néstor Garcia Canclini (2008) coloca que no consumo cultural, a comunicação eficaz ocorre quando há interações e trocas entre os meios e os públicos, assim, opondo-se à condição de passividade; no processo de decodificação, o receptor também é um produtor de sentidos, já que pode assimilar, rejeitar, negociar e alterar de função aquilo que os emissores propõem. Canclini (2008) discorda da ideia de que o chamado público seja um conjunto homogêneo que age da mesma forma. "O público é uma soma de setores que pertencem a estratos econômicos e educativos diversos, com hábitos de consumo cultural e disponibilidade diferentes para relacionar-se com os bens oferecidos no mercado" (CANCLINI, 2008: 150-151).

Isso significa que as formas de decodificação são diferenciadas de acordo com a característica de cada grupo social e a produção de sentidos vai depender de alguns fatores que interferem no sujeito, emissor e/ou receptor, inserido no processo de comunicação: habilidades de comunicação, atitudes, níveis de conhecimento e sistema sociocultural, conforme defende David Berlo:

nosso objetivo básico na comunicação é tornarmo-nos agentes influentes, é afetarmos os outros, nosso ambiente físico e nós próprios, é tornarmo-nos agentes determinantes, é termos opção no andamento das coisas. Em suma, nós nos comunicamos para influenciar - para afetar com intenção (BERLO, 1985: 22).

Este conjunto de significados decodificados pode influenciar, entreter, instruir, persuadir, ou ainda, "ter consequências perceptivas, cognitivas, emocionais, ideológicas ou comportamentais muito complexas" (HALL, 2003: 390). Assim, tanto o recebimento, a compreensão como o uso que as audiências fazem das mensagens decodificadas não podem ser entendidos apenas como um fator comportamental, mas como reflexo das relações econômicas, sociais que moldam a recepção e permitem que os discursos sejam colocados em práticas ou utilizados social ou politicamente. Por outro lado, se o sentido não é articulado em prática, ele não tem efeito e pode comprometer a continuidade do fluxo de produção, ou seja, a reprodução.

Hall (2003) explica que a transmissão da mensagem tem dois momentos distintos: no primeiro, o emissor da comunicação emprega um código para produzir uma 
mensagem; no segundo momento, a mensagem é decodificada pelo receptor em práticas sociais. O diagrama (Figura 1) mostra que os códigos podem não ser perfeitamente simétricos e os graus de compreensão ou não compreensão da mensagem presente na troca comunicativa "dependem dos graus de simetria/ assimetria (relações de equivalência) estabelecidos entre as posições das 'personificações' - codificador-produtor e decodificador-receptor" (HALL, 2003: 391). O autor ressalta ainda que os graus de identidade entre os códigos também interferem no conteúdo transmitido. A falta de adequação dos códigos, sejam verbais ou visuais, reflete nas diferenças estruturais de relação e posição entre transmissores e audiência.

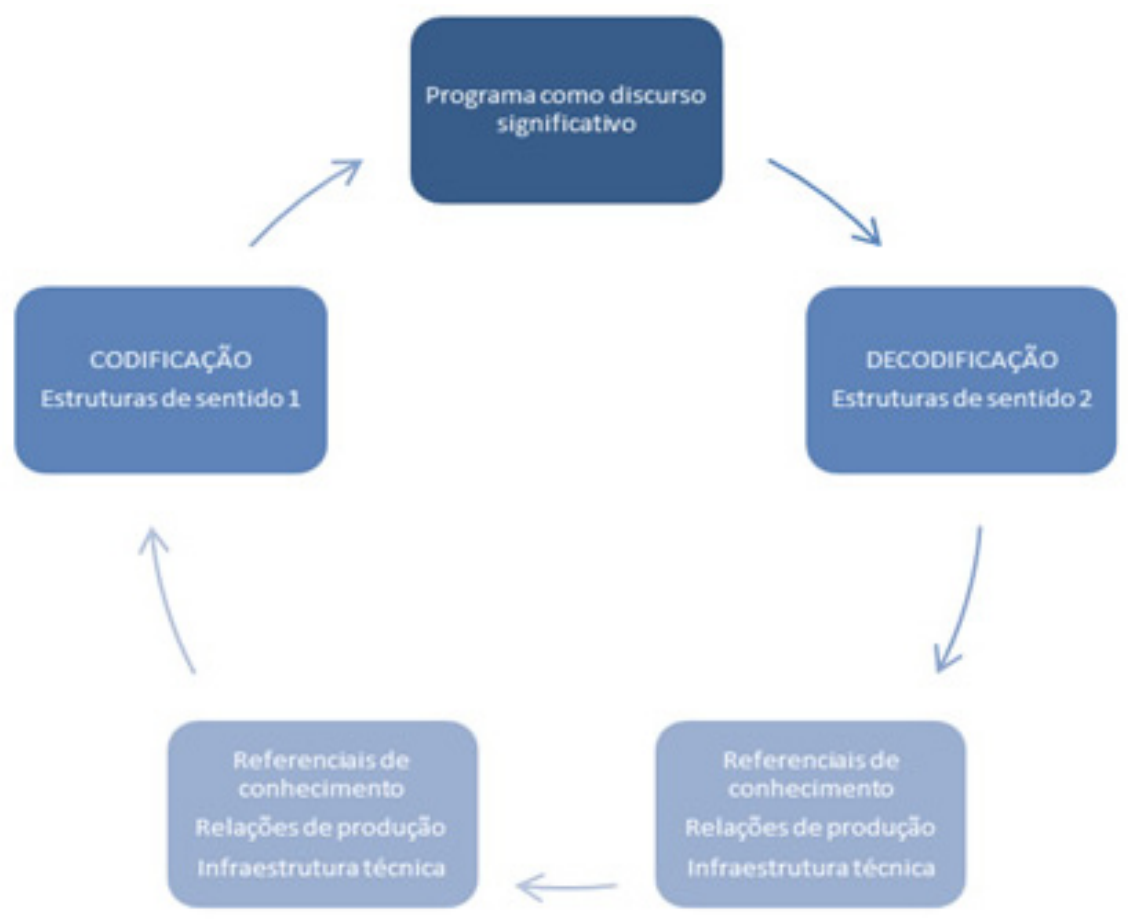

Figura 1: Representação do diagrama de Stuart Hall ( HALL, 2003: 391) Fonte: Elaborada pela autora.

É neste contexto que se insere a revista Sesinho, uma publicação do SESI - Serviço Social da Indústria, criada há 65 anos, cujo conteúdo vem sendo consumido por diferentes gerações, com codificações diferenciadas de suas mensagens, porém, com o mesmo objetivo: que na decodificação, ganhem significação e influenciem sua audiência de acordo com o discurso de seus mantenedores e produtores.

No decorrer de sua história a publicação já teve mais de 250 edições impressas e, diante do volume do acervo, foi necessária uma seleção para a viabilidade deste estudo. Assim, optou-se por edições que representassem as diferentes décadas em que ela foi produzida. Ressalta-se também que a revista Sesinho é o objeto de estudo de um projeto de pesquisa no Programa de Mestrado em Comunicação Visual da Universidade Estadual de Londrina em que vários estudos estão sendo conduzidos a partir do acervo referente ao período de 2001 a 2011.

Neste ensaio, a delimitação do objeto de estudo inclui as capas da revista Sesinho, referentes às diferentes décadas de sua publicação, entre 1940 e 1960, e as capas produzidas na primeira década do século XXI, que constituem uma forma de linguagem utilizada pelo SESI na veiculação de seu discurso, dirigido à infância. O estudo da codificação ocorre nos dois momentos, enquanto a decodificação é analisada de forma qualitativa, referente a uma amostragem das publicações da segunda fase.

O discurso do SESI foi codificado, em épocas distintas, em linguagens específicas para a produção de sentido de sua audiência, para que ela pudesse decodificá- 
${ }^{1}$ Disponível em <http://www. portaldaindustria.com.br/sesi/ institucional/2012/03/1,1792/historia. html>. Acesso em 20 Jul. 2012.

\footnotetext{
${ }^{2}$ Disponível em: <http://www. portaldaindustria.com.br/sesi/ iniciativas/programas/sistema-sesi-deensino/2012/05/1,2878/o-sistema.html >. Acesso em 20 Jul. 2012.
}

\footnotetext{
${ }^{3}$ Disponível em: <http://www.fiepr.org. br/centrodememoria/FreeComponent14926content118563Page2.shtml>. Acesso em 26 Jul. 2012. eeComponent14926content118563Page2.shtm/>. Acesso em $26 \mathrm{Jul} .2012$

${ }^{4}$ Disponível em:<http://www.fiepr.org. br/centrodememoria/FreeComponent8131content48462.shtml >. Acesso em 26 Jul. 2012.
}

las em práticas sociais, de acordo com os interesses da entidade. Por meio da análise da codificação e da decodificação da revista Sesinho, pode-se entender a longevidade do material, o seu impacto no planejamento comunicacional da entidade e o teor destes discursos, por meio da análise dos códigos visuais e verbais presentes na publicação.

\section{Revista Sesinho - seis décadas de história}

O SESI - Serviço Social da Indústria - é uma entidade de direito privado, mantida e administrada pela indústria. Foi fundado em 01 de julho de 1946 através do Decreto-Lei no 9.403, que atribuiu à Confederação Nacional da Indústria (CNI) a sua criação, direção e organização. O surgimento da entidade ocorreu em função da mobilização de empresários "que despertaram o governo para a necessidade de promover a integração e a solidariedade entre patrões e empregados" (SESI, $2012)^{1}$. A entidade propõe-se a melhorar a qualidade de vida dos trabalhadores da indústria e seus dependentes através de atividades que incluem serviços nas áreas de saúde, educação, lazer, cultura, nutrição e promoção da cidadania. O SESI tem sua sede nacional em Brasília e atualmente está presente nos 26 estados do Brasil e no Distrito Federal através de Departamentos Regionais, que representam suportes locais para empresários da indústria de 2006 municípios.

No setor de educação, o Sistema SESI de Ensino oferece educação básica e continuada para os trabalhadores da indústria e seus dependentes. Com "a proposta de formar pessoas para o mundo do trabalho, as escolas do SESI estimulam a criatividade, a capacidade de inovação, o empreendedorismo, a responsabilidade social e ambiental dos estudantes sejam eles crianças, jovens ou adultos" (SESI, 2012)2.

Para isso, mantém programas que envolvem a educação infantil, ensino médio e fundamental, cursos profissionalizantes, alfabetização e educação básica para jovens e adultos. A entidade montou estruturas, dentre as quais se destaca a Rede de Colégios SESI e metodologias próprias para atender filhos de industriários e a comunidade onde os colégios estão instalados.

A revista Sesinho tem por objetivo transmitir conhecimentos variados, baseados em princípios e valores como cidadania, solidariedade, companheirismo, ética, comportamento, moral e diversão (SISTEMA FIEP, 2012). Para atingir os objetivos, a revista tem uma estrutura na qual consta uma história em quadrinhos com uma temática específica desenvolvida pelos personagens da Turma do Sesinho e seções internas com passatempos, curiosidades, correspondências que reforçam a temática central da revista. Além de ser um recurso pedagógico usado regularmente na Rede de Colégios SESI, no contexto da comunicação organizacional, a revista representa um canal de comunicação entre a entidade e o público infantil, aspecto reforçado pela entidade quando afirma que "a revista do Sesinho é o porta-voz do SESI junto às crianças. Seu personagem principal é um menino [...] que vive experiências semelhantes às de seu público alvo" (SISTEMA FIEP, 2012) ${ }^{3}$.

A publicação foi criada em 1947 "para divertir e educar toda uma geração, tendo como personagem principal o menino Sesinho, exemplo de menino: educado, 'gente boa', honesto e amigo, capaz de grandes gestos para auxiliar as pessoas" (SISTEMA FIEP, 2012) ${ }^{4}$. A revista, criada e produzida pelo jornalista, poeta, contista e historiador Vicente Guimarães, era vendida em bancas e, após 154 edições, parou de circular em 1960. A publicação da Sesinho ocorreu num período marcado pela desconfiança em relação às histórias em quadrinhos, pois, conforme Waldomiro Vergueiro (2004), entre os anos de 1945 e 1950 uma campanha iniciada nos Estados Unidos e estendida para outros países alertava contra os pretensos malefícios que a leitura de histórias em quadrinhos poderia causar no público adolescente. 
A partir da década de 1960, com o desenvolvimento das Ciências da Comunicação e dos estudos da comunicação em várias partes do mundo, as histórias em quadrinhos aproximaram-se das práticas pedagógicas e, na década de 1990, no Brasil, autores de livros didáticos passaram a diversificar a linguagem, incorporando a linguagem dos quadrinhos em suas produções. Foi neste contexto que a revista Sesinho voltou a ser produzida em 1995, apenas em meio eletrônico, utilizando a mídia CD Rom. Seis anos depois, voltou a ser impressa e, com uma tiragem de um milhão de exemplares passou a ser distribuída gratuitamente nas escolas da Rede SESI e em outros 12 mil endereços, incluindo empresas, ONGs e universidades.

A segunda fase de publicação da revista Sesinho ocorreu num período em que a valorização das histórias em quadrinhos é formalizada pelo governo brasileiro, que prevê a sua utilização como recurso didático pedagógico, na Lei de Diretrizes e Base (LDB) e nos Parâmetros Curriculares Nacionais (PCN). Outra decisão que reforça o interesse e a valorização das $\mathrm{HQs}$ foi a inclusão desta modalidade de linguagem iconográfica na lista anual de compras de livros do Programa Nacional Biblioteca da Escola.

\section{Revista Sesinho - codificação e decodificação}

Neste trabalho foram selecionadas, de forma aleatória, capas das décadas de 1940, 1950 e 1960 (Quadro1), que representam a primeira fase da publicação. Na segunda fase foram selecionadas, também de forma aleatória, três capas que representam o início, meio e fim da primeira década de relançamento da revista, que compreende o período de 2001 a 2011(Quadro 2).

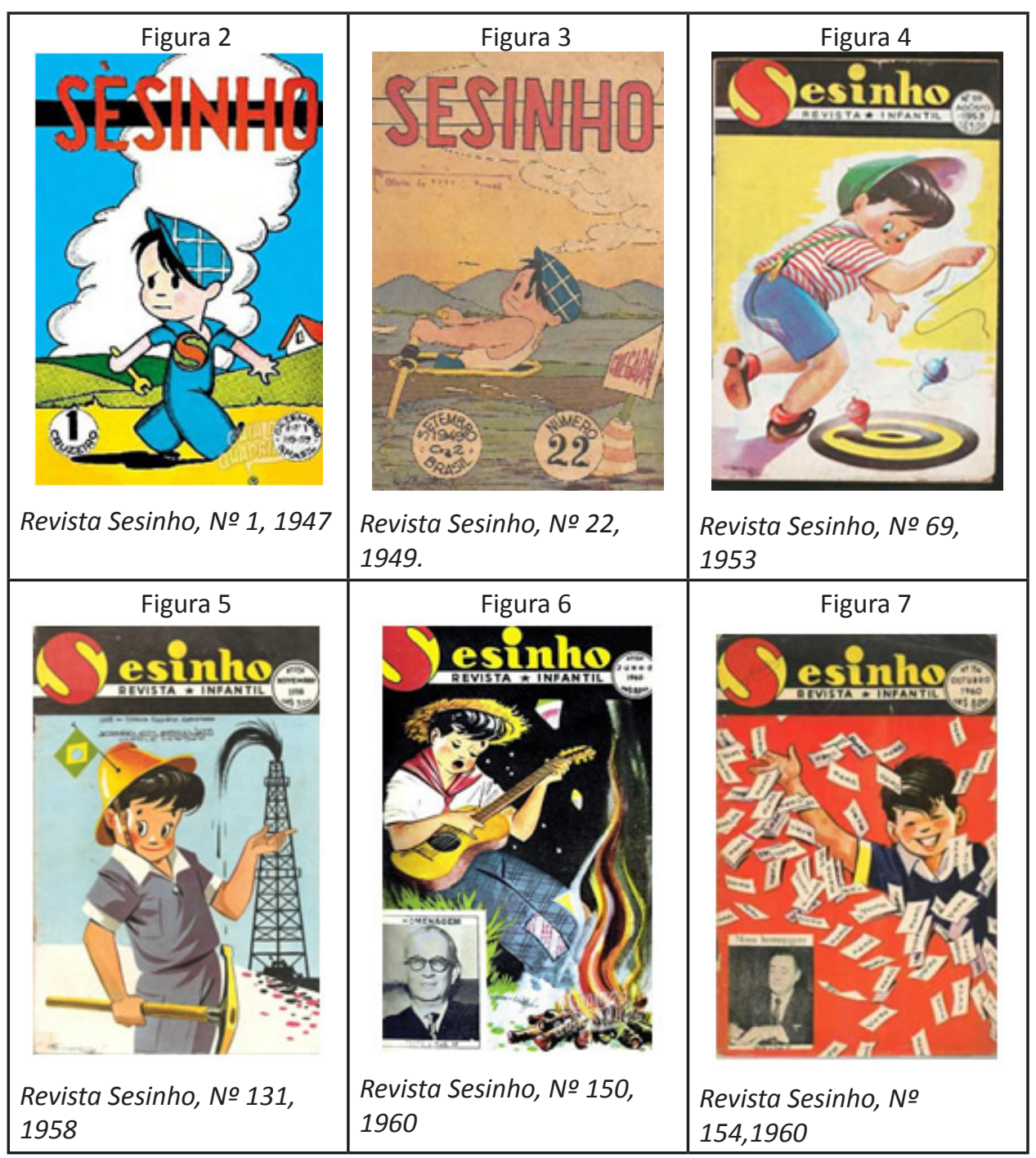

Quadro 1: Revista Sesinho - 1947 / 1960.

Fonte: Guia dos Quadrinhos 2012 (Disponível em: <www.guiadosquadrinhos.com>.) 
Para Will Eisner (2010) as histórias em quadrinhos têm uma linguagem baseada na experiência visual comum ao criador e ao público. A construção de narrativas com signos verbais e visuais tem o objetivo de permitir uma leitura de fácil compreensão da mistura imagens-palavras. É necessário que durante a leitura se desenvolva uma interação, em que as mensagens sejam comuns tanto para o criador como para o leitor.

A configuração geral da revista em quadrinhos apresenta uma sobreposição de palavra e imagem, e assim, é preciso que o leitor exerça suas habilidades interpretativas visuais e verbais. As regências da pintura (por exemplo, perspectiva, simetria, pincelada) e as regências da literatura (por exemplo, gramática, enredo, sintaxe) superpõem-se mutuamente. A leitura da revista em quadrinhos é um ato de percepção estética e de esforço intelectual (EISNER, 2010: 8).

Uma característica da linguagem dos quadrinhos é a utilização de imagens repetitivas e de símbolos reconhecíveis, que são utilizados com frequência para expressar ideias similares. A interação e a compreensão da mensagem ocorrem quando o leitor reconhece o significado e o impacto emocional das imagens, "portanto, a competência da representação e a universalidade da forma escolhida são cruciais" (EISNER, 2010: 14). O reconhecimento das imagens e suas respectivas mensagens ocorrem, primeiramente, com o contato das imagens presentes na capa da publicação, momento crucial para despertar a atenção e o interesse do leitor. É na capa que o leitor identifica o principal conteúdo da publicação, evidencia personagens e temas que serão tratados no decorrer da narrativa.

Nas primeiras capas da revista Sesinho o foco é o personagem principal e os elementos que retratam cenas de seu cotidiano. Neste período, o objetivo do SESI foi utilizar a revista para preparar a infância para o mundo do trabalho, daí a representação do menino Sesinho como trabalhador (Figuras 2 e 5). A representação da atividade profissional ocorre nos uniformes e nas ferramentas portadas pelo personagem, normalmente relacionados aos segmentos da indústria, classe representada pelo SESI. Segundo a historiadora Olga Brites (1993), o planejamento que Sesinho tem para infância incluiu ainda, naquela época, temas relacionados à Ciência, Religião, Razão, Fantasia, Saúde, Higiene e Alimentação. Nas figuras 3 e 4 os temas estão relacionados ao esporte e lazer, na figura 6 a representação do homem do campo e seu costume de tocar viola ao redor da fogueira e, na figura 7, a representação de Sesinho envolto em cédulas de votação, em uma alusão às eleições.

Segundo Brites (1993) o estudo histórico da publicação não mostra a infância apenas como dimensão natural da vida humana, mas um discurso específico para uma parte da população brasileira - a família industriária - indicando, por meio da narrativa da revista, tarefas, disciplinas, comportamentos, sempre vinculados ao viés do trabalho. A nação é o espaço concreto para a implantação deste projeto, daí a utilização de símbolos nacionais (figura 5), que ocorrerá repetidamente em diversas publicações. A codificação da mensagem do SESI utiliza elementos como personagens, datas, valores, ferramentas, vestuário que aproximam a entidade dos filhos de industriários, pois são elementos que fazem parte do repertório do público-alvo, e que permitem uma decodificação com níveis de significados equivalentes aos conteúdos que a entidade deseja transmitir.

A compreensão da imagem requer um compartilhamento de experiências e, na elaboração dos quadrinhos, os autores devem compreender a experiência de vida do leitor para que a mensagem atinja seu objetivo (EISNER, 2010). É desta forma que revista Sesinho adapta seu discurso para a infância, pois as mensagens são transmitidas utilizando fatos e acontecimentos do cotidiano de um grupo de 
crianças, as quais descobrem, por meio de suas experiências, normas e valores da vida em sociedade, propostas de acordo com a visão dos produtores e mantenedores da revista.

Adriano Duarte Rodrigues (1999), em seu trabalho sobre Experiência, Modernidade e Campos dos Media aponta que a experiência compreende um conjunto de saberes formados de crenças firmes, fundamentadas no hábito. A experiência compreende três domínios fundamentais e originários: os domínios das experiências de si próprio, dos outros e do mundo natural.

Este conjunto de saberes que tenho de aceitar como seguros, pelo hábito, e não porque a razão me dê provas categóricas da sua verdade, e que tem a ver com a existência de mim próprio, dos outros e do mundo natural, constitui aquilo a que dou o nome de dimensão ontológica da experiência (RODRIGUES, 1999: p.4-5).

Esta dimensão se fundamenta no que o autor denomina sistema de expectativas, que constitui um

sistema simbólico e é com base nele que, por um lado, regulo a minha vida de acordo com aquilo que considero razoável e adequado ao comportamento dos outros e ao desenrolar dos fenômenos da natureza e que, por outro lado, interpreto os comportamentos dos outros e os fenómenos da natureza de acordo com aquilo que me habituei a esperar desses comportamentos e desses fenómenos (RODRIGUES, 1999: 7).

Assim, o discurso do SESI se pauta na experiência apresentada ao público para regular outras experiências que ele poderá vivenciar. Este direcionamento está presente nas edições da primeira fase e tem continuidade, nas publicações do século XXI, com adaptações ao período histórico e social de cada época (Quadro 2).

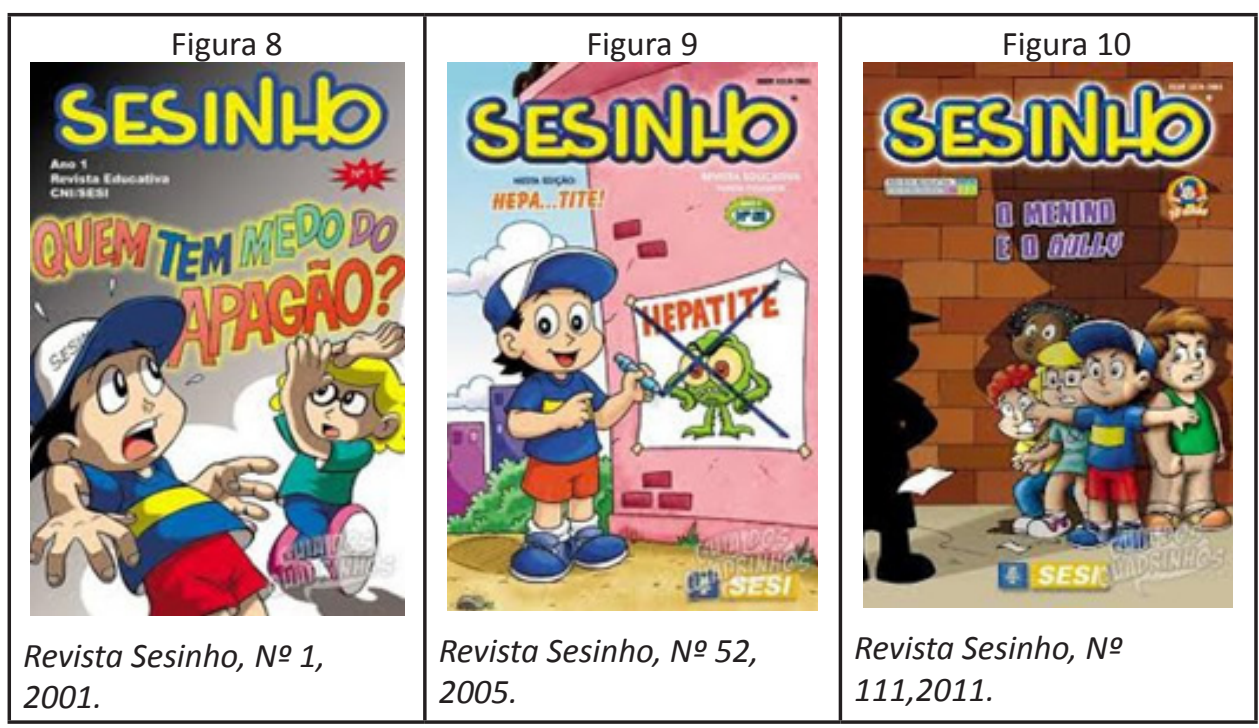

Quadro 2: Revista Sesinho-2001/2011.

Fonte: Guia dos Quadrinhos 2012 (Disponível em: <www.guiadosquadrinhos.com>.)

A primeira capa da Revista Sesinho, em sua segunda fase, tem como título "Quem tem medo do apagão?" (Figura 8) e foi publicada em julho de 2001. A história refere-se à crise do apagão, uma crise nacional que ocorreu no país no período de julho de 2001 a setembro de 2002 e que afetou o fornecimento e distribuição de energia elétrica. Como o fato atingiu diretamente a indústria brasileira, o tema foi abordado e apresentado ao público infantil, pois as famílias tiveram que mudar os hábitos de consumo. Na capa de outubro de 2005 (Figura 9), o tema principal é a 
saúde, um dos principais enfoques da revista, tanto na primeira como na segunda fase da publicação. Em 2011, a capa trata de um assunto que afeta diretamente a vida das crianças, o bullyng, mostrando uma situação ameaçadora, caracterizada por atos agressivos verbais ou físicos, de maneira repetitiva, por parte de um ou mais alunos contra uma criança ou um grupo, como representado na capa da edição no 111 ( Figura 10).

Em sua segunda fase de publicação, o aspecto que mais chama a atenção nas capas da revista Sesinho é que o personagem principal não é mais mostrado como pequeno trabalhador, mas sempre como criança, por meio do vestuário - shorts, camiseta, tênis e o boné, um acessório que é reproduzido em todas as imagens do personagem, incluindo a palavra Sesinho, para reforçar o nome do personagem. O discurso do SESI, ao tratar de temas do cotidiano da criança é adaptado ao contexto histórico e social do país, que não mais aceita o trabalho infantil. 0 direcionamento da revista segue o que é preconizado no Estatuto da Criança e do Adolescente, promulgado em 13 de julho de 1990, e adere ao movimento nacional em prol dos direitos das crianças e adolescentes.

Os temas apresentados nas capas tratam novamente de assuntos do cotidiano do grupo de crianças, ora tratando de experiências vividas por eles, como é o caso do bullying, ora de experiências que fazem parte do contexto social em que estão inseridos - por exemplo, quando abordam a crise do apagão-ou ainda de situações que poderão ainda ser vivenciadas, e por isso devem fornecer informações sobre elas, como é o caso da capa sobre a doença hepatite. Analisando a codificação das capas da revista Sesinho conclui-se que, em sua primeira fase, a publicação trabalhava basicamente com os temas voltados para educação, saúde e trabalho e em sua segunda fase, ela ressaltava temas relacionados à ética, comportamentos, moral e diversão, porém, utilizando sempre a mesma estratégia, de colocar seus personagens em situações semelhantes às experiências que podem ser vivenciadas ou imaginadas por seus leitores.

A análise da decodificação está diretamente ligada ao receptor, neste caso, a identificação da criança com os personagens fortalece a relação com o emissor das mensagens. Existem várias possibilidades de análise da recepção deste produto comunicativo e, para esta análise, uma das formas de identificar a percepção do público é por meio da seção fixa de cartas, disponibilizada pela revista para manter a comunicação com os leitores. Todos os meses a publicação registra uma média de 500 cartas de crianças e adultos que compartilham suas experiências com o personagem e mostram como foram atingidos pelas mensagens da revista (SISTEMA FIEP, 2012). Mensalmente são selecionadas e publicadas uma média de dez cartas na revista Sesinho, nas seções Sesinho Responde e Galeria do Sesinho, espaço dedicado à reprodução dos desenhos enviados pelos leitores. Com estas seções, cria-se mais um vínculo com o público alvo, em que o compartilhamento de percepções e de experiências é mais evidente.

${ }^{5}$ Na Revista Sesinho no 1 não há correspondências, pois, sendo a primeira edição, os editores fizeram o convite para que os leitores participassem com envio de cartas e desenhos.
As cartas analisadas nas revistas Sesinho ( $n$ o 52 e no 111$)^{5}$ mostram que, mesmo enviadas por crianças, os conteúdos têm a participação de pais, professores e mesmo dos editores da revista, que resumem os conteúdos e publicam com as respectivas respostas em nome do personagem principal. As correspondências abordam assuntos como: solicitação de envio de revistas, sugestão de assuntos para publicações posteriores, comentários dos temas das edições anteriores e até reclamações pela demora da resposta e da publicação da carta, mostrando que, além de falar com o personagem, o público deseja fazer parte da publicação, seja por meio das cartas ou dos desenhos.

\section{Considerações finais}

Dentro do modelo de Stuart Hall, a análise das capas da revista Sesinho em épocas distintas permite verificar que a comunicação do SESI com o público 
infantil manteve uma estrutura produzida e sustentada nas fases de produçãocirculação, distribuição e consumo, para manter e garantir a existência e o leitura da publicação por mais de seis décadas. A linguagem iconográfica dos quadrinhos, por meio dos códigos verbais e visuais, foi utilizada para compor o discurso da entidade e estimular sua recepção pelos leitores.

Confirmando o estudo de HALL (2003), o objetivo da mantenedora é que, ao atingir seu público alvo, o produto comunicativo - revista Sesinho - seja entendido e transformado em práticas sociais, ou seja, que seus efeitos se traduzam em mudanças de comportamento e aceitação do discurso proposto. Nas capas analisadas, o conteúdo trata de experiências comuns do personagem e do leitor e mostram situações e formas de agir diante delas. Assim, o circuito do processo de comunicação se completa e produz seus efeitos. As mensagens da revista são apropriadas num discurso significativo e sua linguagem permite que o leitor as decodifique predominantemente de acordo com a intenção e objetivos dos produtores.

Os significados decodificados pelos leitores da revista Sesinho influenciam, entretêm e podem ter consequências perceptivas, cognitivas, emocionais, ideológicas e comportamentais (HALL, 2003). A existência da publicação e seu consumo num período de seis décadas mostra que a produção de sentido permaneceu e não comprometeu a continuidade do fluxo de produção, ou seja, mesmo em épocas distintas e atingindo públicos em diferentes contextos sociais, sua reprodução permanece inalterada e os discursos sendo colocados em prática ou utilizados social e politicamente. Isso ocorre porque as estruturas de sentido, tanto na codificação, como na decodificação, sustentam-se na utilização de códigos compreensíveis aos leitores, relacionados ao compartilhamento de experiências de vida comuns entre produtores e receptores da revista Sesinho.

\section{Referências Bibliográficas}

BERLO, David. O proceso da comunicação: introdução à teoría e à prática. São Paulo: Martins Fontes, 1985.

BRITES, Olga. Saúde e educação para o trabalho em Sesinho (1947/1960). Rev. hist., São Paulo, n. 127-128, jul. 1993. Disponível em: <http://www.revistasusp. sibi.usp.br/pdf/rh/n127-128/07.pdf>.

CANCLINI, N.G.Culturas Híbridas: Estratégias para Entrar e Sair da Modernidade. Tradução Heloísa Pezza Cintrão, Ana Regina Lessa: tradução da introdução Gênese Andrade - 4 ed. 3 reimpr. - São Paulo: Editora da Universidade de são Paulo,2008.

EISNER, Will. Quadrinhos e arte seqüencial: princípios e práticas do lendário cartunista /Will Eisner; traduçãoLuis Carlos Borges, Alexandre Boide. 4a edição. São Paulo:Editora WMF Martins Fontes,2010.

GUIA DOS QUADRINHOS 2012. Disponível em: $<\mathrm{http}: / /$ www.guiadosquadrinhos.com/thumb.aspx?cod_tit=se191200\&esp=\&total=122. . Acesso em: 12 jul. 2012>.

HALL, Stuart. Da Diáspora Identidades e Mediações Culturais. Editora UFMG, Belo Horizonte, 2003.

RODRIGUES, Adriano Duarte. Experiência, Modernidade e Campos dos Media. Universidade Nova de Lisboa, 1999. Disponível: <http://bocc.ubi.pt/pag/ rodrigues-adriano-expcampmedia.html>. 
RODRIGUES, Adriano Duarte. Comunicação e Cultura: a experiência cultural na era da informação. Editorial Presença, Lisboa, 1993.

SESI, Serviço Social da Indústria. Disponível em: <http://www.portaldaindustria. com.br/sesi/institucional/2012/03/1,1792/historia.html>. Acesso em: 20 jul. 2012.

SESI, Serviço Social da Indústria. Disponível em: <http://www.portaldaindustria. com.br/sesi/iniciativas/programas/sistema-sesi-de-ensino/2012/05/1,2878/osistema.html>. Acesso em 20 jul.2012.

SISTEMA FIEP, Federação das Indústrias do Estado do Paraná. Disponível em: <http://www.fiepr.org.br/centrodememoria/ FreeComponent14926content118563Page2.shtml>.Acesso em: 26 jul. 2012.

SISTEMA FIEP, Federação das Indústrias do Estado do Paraná. Disponível em <http://www.fiepr.org.br/centrodememoria/FreeComponent8131content48462. shtml>. Acesso em 26 jul. 2012.

VERGUEIRO, Valdomiro (org.) Como usar as histórias em quadrinhos em sala de aula. São Paulo: Contexto, 2004. 